\title{
Genetic characterization of Toxoplasma gondii from cats in Yunnan Province, Southwestern China
}

\author{
Yi-Ming Tian ${ }^{1,2+}$, Si-Yang Huang ${ }^{2+}$, Qiang Miao ${ }^{1,2+}$, Hai-Hai Jiang ${ }^{2}$, Jian-Fa Yang ${ }^{1}$, Chunlei Su, ${ }^{2,3}$, Xing-Quan Zhu ${ }^{1,2}$ \\ and Feng-Cai Zou ${ }^{1,4^{*}}$
}

\begin{abstract}
Background: Cats are the definitive hosts of Toxoplasma gondii. The distribution of genetic diversity of T. gondii in cats is of importance to understand the transmission of this parasite. The objective of this study was to genetically characterize T. gondii isolates from cats in Yunnan province, southwestern China.

Methods: Genomic DNA was extracted from 5-10 g cat tissue samples (brain, tongue, heart, and liver). Using multilocous polymerase chain reaction-restriction fragment length polymorphism (PCR-RFLP) technology, we determined genetic diversity of $T$. gondii isolates from cats in Yunnan province.

Result: In total, 175 stray cats were tested for T. gondii DNA, respectively, 44 (25.14\%) of which were found to be positive for the $T$. gondii B1 gene by PCR amplification. The positive DNA samples were typed at 11 genetic markers, including 10 nuclear markers, namely, SAG1, 5'-3'SAG2, alternative SAG2, SAG3, GRA6, L358, PK1, BTUB, C22-8, C29-2 and an apicoplast locus Apico. Of these, 16 isolates from cats were genotyped with data for more than 9 loci, revealed 5 genotypes in total, of which 11 of 16 samples were identified as ToxoDB\#9, two samples may belong to genotye \#225, one was Type II, one was ToxoDB\#3, and one was ToxoDB\#20 (http://toxodb.org/toxo/).

Conclusions: The results of the present study indicated a wide distribution of $T$. gondii infection in cats in Yunnan province, which may pose significant public health concerns. To our knowledge, the present study is the first report of T. gondii prevalence and genotypes in cats in southwestern China, and the first report of Type II T. gondii from cats in China.
\end{abstract}

Keywords: Toxoplasma gondii, Cats, Genetic characterization, Multilocus PCR-RFLP, Yunnan

\section{Background}

Toxoplasma gondii is an obligate intracellular parasite that has a remarkable ability to infect almost all warm-blooded animals, including humans [1]. It is transmitted to humans through consumption of undercooked meat containing T. gondii tissue cysts, or by food or water contaminated with oocysts shed in the feces of infected cats. T. gondii establishes a lifelong chronic infection in the host. Though the infection rarely causes clinical symptoms in healthy

\footnotetext{
* Correspondence: zfc1207@vip.163.com

${ }^{\dagger}$ Equal contributors

'College of Animal Science and Technology, Yunnan Agricultural University, 650201 Kunming, Yunnan Province, PR China

${ }^{4}$ School of Life Sciences, Yunnan University, 650091 Kunming, Yunnan Province, PR China

Full list of author information is available at the end of the article
}

adults, it can be fatal in immunocompromised individuals, such as AIDS patients or patients undergoing immunosuppressive therapy [2]. Cats are the only known animals that serve as the definitive hosts where sexual multiplication of the parasite occurs, resulting in excreting oocysts into the environment which may be a potential source of infection for all types of warm-blooded animals [1].

T. gondii strains isolated from Europe and North America belong to three distinct clonal lineages, Types I, II, and III, which differ in many phenotypes, including pathogenicity, and a fourth clonal lineage (type 12) in North America was identified in wildlife recently [3]. However, T. gondii strains from South America are genetically more diverse [4-6]. 
China is a large country, but limited information concerning genetic characterization of $T$. gondii isolates from cats is available [7-11]. The climate in China differs from region to region because of the country's highly complex topography, thus, the genetic diversity of $T$. gondii isolates could be different. Yunnan is a province located in the far southwest of the country, it has complex topography and diverse climate. Seroprevalence rates of $T$. gondii infection in this province are $35 \%, 24 \%, 22 \%, 17 \%$ and $13 \%$ for HIV positive patients, HIV negative control, pet dogs, pigs and peafowls, respectively, indicating wild distribution of $T$. gondii infection in this region [12-15]. However, there is no epidemiology or genotype information on T. gondii in cats here. Genetic analysis of $T$. gondii infection in cats is of importance to understand the epidemiology, transmission patterns and mechanisms of the disease. Thus, the objectives of this study were to determine the prevalence and genetically characterize $T$. gondii in cats in Yunnan province, southwestern China.

\section{Methods}

\section{Ethics statement}

The present study was approved by the Animal Ethics Committee of Lanzhou Veterinary Research Institute, Chinese Academy of Agricultural Sciences (Approval No: LVRIAEC2011-007). All cats were handled in strict accordance with good animal practice according to the Animal Ethics Procedures and Guidelines of the People's Republic of China.

\section{Sample collection}

A total of 175 stray cats were collected randomly from Yunnan province during June 2011 to June 2012, these cats came from different cities of Yunnan, including 43 from Jinping, 23 from Nujiang, 4 from Kunming, 54 from Eryuan, 13 from Banna, and 38 from Yimen. Most of the cats were collected dead, thus, the information about breed and age of these cats were not available. Tissue samples (brain, tongue, heart, and liver) were collected from the cats for T. gondii detection. All tissue samples were stored at $-20^{\circ} \mathrm{C}$ prior to use.

\section{Genomic DNA extraction}

Genomic DNA was extracted from cat tissue samples using TIANamp Genomic DNA kit (TianGen ${ }^{\mathrm{TM}}$, Beijing, China) according to manufacturer's recommendations. In brief, $30 \mathrm{mg}$ of each tissue were treated with sodium dodecyl sulphate/proteinase $\mathrm{K}$ at $56^{\circ} \mathrm{C}$ for overnight digestion in thermostat water bath. DNA samples were prepared after purification by silica gel column chromatography and eluted into $50 \mu \mathrm{L}$ elution buffer.

\section{Genetic characterization of $T$. gondii isolates}

The DNA samples from cat tissues were first screened for $T$. gondii infection using semi-nested PCR of the B1
Table 1 Prevalence of Toxoplamsa gondii infection in cats detected by PCR in different cities in Yunnan province, southwestern China

\begin{tabular}{lccc}
\hline Region & Total no. & Positive no. & Prevalence (\%) \\
\hline Jinping & 43 & 11 & 25.58 \\
Nujiang & 23 & 9 & 39.13 \\
Kunming & 4 & 1 & 25 \\
Eryuan & 54 & 8 & 14.81 \\
Banna & 13 & 4 & 30.77 \\
Yimen & 38 & 11 & 28.95 \\
Total & 175 & 44 & 25.14 \\
\hline
\end{tabular}

gene [16] and then the positive samples were genotyped using Multi-locus PCR-RFLP (Mn-PCR-RFLP) method [17]. In brief, the target DNA sequences were amplified by multiplex PCR using external primers for all 11 markers. The reaction volume consisted of $25 \mu \mathrm{l}$ containing $100 \mathrm{ng}$ genomic DNA with positive control samples. Nine T. gondii strains were included as the positive controls (Table 1). The PCR reaction composed of $1 \times$ PCR buffer, $0.2 \mathrm{mM}$ of each primer, $200 \mu \mathrm{M}$ dNTPs, $2 \mathrm{mM} \mathrm{MgCl} 2,0.2$ $\mathrm{U}$ of HotStart Taq DNA polymerase (TAKARA, Japan). The PCR amplification was performed using thermal cycler (PTC 200, Bio-RAD). All samples were incubated at $95^{\circ} \mathrm{C}$ for $5 \mathrm{~min}$ to activate the DNA polymerase, then 30 cycles of PCR at $95^{\circ} \mathrm{C}$ for $30 \mathrm{~s}, 55^{\circ} \mathrm{C}$ for $60 \mathrm{~s}$ and $72^{\circ} \mathrm{C}$ for $90 \mathrm{~s}$. Then $1 \mu \mathrm{L}$ of the products served as template DNA for nested PCR with internal primers for each marker, respectively. A similar program was used for the nested PCR. The nested PCR was carried out with an annealing temperature at $60^{\circ} \mathrm{C}$ for $60 \mathrm{~s}$ for all the markers except Apico, which was amplified at $55^{\circ} \mathrm{C}$. The nested PCR products were digested with restriction enzymes for $1 \mathrm{~h}$, and the temperature for each enzyme followed the instruction for each enzyme. The restriction fragments were resolved in $2.5 \%-3 \%$ agarose gel to display DNA fragment length polymorphism using a gel document system (UVP GelDoc- $\mathrm{It}^{\mathrm{TM}}$ Imaging System, Cambridge, U.K.).

\section{Statistical analyses}

Results were analyzed with SPSS for Windows (Release18.0 standard version, SPSS Inc., Chicago, Illinois). Generalized Lineal Model (GLM) test was used to analyze the

Table 2 Prevalence of Toxoplasma gondii infection in cats detected by PCR in different tissues

\begin{tabular}{cccc}
\hline Tissues & Total no. & Positive no. & Prevalence (\%) \\
\hline Brain & 175 & 26 & 14.85 \\
Liver & 164 & 18 & 10.98 \\
Heart & 175 & 25 & 14.28 \\
Tongue & 172 & 27 & 15.7 \\
\hline
\end{tabular}


Table 3 Summary of genotyping of Toxoplasma gondii in stray cats in Yunnan Province (Yn), southwestern China

\begin{tabular}{|c|c|c|c|c|c|c|c|c|c|c|c|c|c|c|c|}
\hline Isolate ID & Host & Tissue & Location & SAG1 & $5^{\prime}+3^{\prime}$ SAG2 & Alt. SAG2 & SAG3 & BTUB & GRA6 & c22-8 & c29-2 & L358 & PK1 & Apico & Genotype \\
\hline GT1 & Goat & & United States & I & I & I & I & I & I & I & I & I & I & I & Reference, Type I, ToxoDB \#10 \\
\hline PTG & Sheep & & United States & $\|/\| \|$ & $\|$ & $\|$ & $\|$ & $\|$ & $\|$ & $\|$ & $\|$ & $\|$ & $\|$ & $\|$ & Reference, Type II, ToxoDB \#1 \\
\hline CTG & Cat & & United States & $\|/\| \|$ & III & III & III & III & III & III & III & III & III & III & Reference, Type III, ToxoDB \#2 \\
\hline MAS & Human & & France & $u-1$ & । & $\|$ & III & III & III & $u-1$ & । & । & III & । & Reference, ToxoDB \#17 \\
\hline TgCgCa1 & Cougar & & Canada & । & $\|$ & $\|$ & III & $\|$ & $\|$ & $\|$ & $u-1$ & । & $\mathrm{u}-2$ & । & Reference, ToxoDB \#66 \\
\hline TgCatBr5 & Cat & & Brazil & I & III & III & III & III & III & I & । & I & $\mathrm{u}-1$ & । & Reference, ToxoDB \#19 \\
\hline TgWtdSc40 & W-t deer & & USA & $u-1$ & $\|$ & $\|$ & $\|$ & $\|$ & $\|$ & $\|$ & $\|$ & । & $\|$ & । & Reference, ToxoDB \#5 \\
\hline TgCatBr64 & Cat & & Brazil & I & I & $\mathrm{u}-1$ & III & III & III & $\mathrm{u}-1$ & । & III & III & । & Reference, ToxoDB \#111 \\
\hline TgToucan & Toucan & & Costa Rica & $u-1$ & । & $\|$ & III & । & III & $u-2$ & । & । & III & । & Reference, ToxoDB \#52 \\
\hline TgCYn1 & Cat & Heart & Eryuan, $\mathrm{Yn}$ & $u-1$ & $\|$ & $\|$ & III & III & $\|$ & $\|$ & III & $\|$ & $\|$ & । & ToxoDB \#9 \\
\hline TgCYn2 & Cat & Heart & Eryuan, Yn & $\mathrm{u}-1$ & $\|$ & $\|$ & III & III & $\|$ & $\|$ & III & $\|$ & $\|$ & I & ToxoDB \#9 \\
\hline TgCYn3 & Cat & Heart & Kunming, Yn & $\mathrm{u}-1$ & $\|$ & $\|$ & III & III & $\|$ & $\|$ & III & $\|$ & $\|$ & I & ToxoDB \#9 \\
\hline TgCYn4 & Cat & Heart & Yimen, Yn & $\|/\|$ & $\|$ & $\|$ & $\|$ & $\|$ & $\|$ & $\|$ & $\|$ & $\|$ & $\|$ & । & Type II, ToxoDB \#3 \\
\hline TgCYn5 & Cat & Liver & Jinping, Yn & $\mathrm{u}-1$ & $\|$ & $\|$ & III & III & $\|$ & $\|$ & III & $\|$ & $\|$ & 1 & ToxoDB \#9 \\
\hline TgCYn6 & Cat & Heart & Jinping, Yn & $\mathrm{u}-1$ & $\|$ & $\|$ & III & III & $\|$ & $\|$ & III & $\|$ & $u-2$ & I & ToxoDB \#20 \\
\hline TgCYn7 & Cat & Tongue & Jinping, Yn & $\|/\| \|$ & $\|$ & $\|$ & $\|$ & $\|$ & $\|$ & $\|$ & $\|$ & $\|$ & $\|$ & $\|$ & Type II, ToxoDB \#1 \\
\hline TgCYn8 & Cat & Tongue & Jinping, $Y n$ & $\mathrm{u}-1$ & $\|$ & $\|$ & III & III & $\|$ & $\|$ & III & $\|$ & $\|$ & । & ToxoDB \#9 \\
\hline TgCYn9 & Cat & Heart & Nujiang, Yn & $\mathrm{u}-1$ & $\|$ & $\|$ & III & III & $\|$ & $\|$ & III & $\|$ & III & 1 & ToxoDB \#9 \\
\hline TgCYn10 & Cat & Tongue & Nujiang, Yn & nd & I & I & III & I & । & I & । & I & I & । & Type I variant 1 \\
\hline TgCYn11 & Cat & Brain & Nujiang, Yn & $u-1$ & $\|$ & $\|$ & III & III & $\|$ & $\|$ & III & $\|$ & III & । & ToxoDB \#9 \\
\hline TgCYn12 & Cat & Brain & Nujiang, Yn & $u-1$ & $\|$ & $\|$ & III & III & $\|$ & $\|$ & III & $\|$ & III & I & ToxoDB \#9 \\
\hline TgCYn13 & Cat & Heart & Nujiang, Yn & $u-1$ & $\|$ & $\|$ & IIII & III & $\|$ & $\|$ & III & $\|$ & III & I & ToxoDB \#9 \\
\hline TgCYn14 & Cat & Tongue & Nujiang, Yn & $u-1$ & $\|$ & $\|$ & III & III & $\|$ & nd & III & $\|$ & III & I & ToxoDB \#9 \\
\hline TgCYn16 & Cat & Brain & Jinping, Yn & $\mathrm{u}-1$ & $\|$ & I & III & III & $\|$ & $\|$ & III & $\|$ & nd & I & ToxoDB \#9 \\
\hline TgCYn17 & Cat & Heart & Banna, Yn & I & I & I & III & 1 & nd & 1 & 1 & I & 1 & 1 & Type I variant 1 \\
\hline
\end{tabular}

$\mathrm{u}-1$ and $\mathrm{u}-2$ represent unique RFLP genotypes, respectively; nd $=$ no data 
prevalence of $T$. gondii in different regions and tissues. The differences were considered to be statistically significant when the P-value was less than 0.05 .

\section{Results and discussion}

Forty-four (25.14\%) out of 175 cats were T. gondii B1 gene positive detected by PCR. The positive samples were distributed in all six administrative cities with the prevalence ranging from $14.81 \%$ (Eryuan) to $39.13 \%$ (Nujiang), but the difference was not statistically significant $(P>0.05)$ (Table 1). The prevalence in different tissues varied from $10.98 \% \%$ (liver) to $15.7 \%$ (tongue), however, there was no significant difference $(P>0.05)$ (Table 2$)$.

Several studies have reported the $T$. gondii prevalence in cats in various regions in China, but little is known of the prevalence of $T$. gondii in cats in Yunnan province. A study reported an overall $21.3 \%$ seroprevalence of $T$. gondii among cats in Lanzhou, northwestern China [18]. The overall prevalence of $T$. gondii exposure in cats in Yunnan province was $25.14 \%$, which is lower than that detected in Guangzhou (79.4\%) [11]. The differences in prevalence of $T$. gondii exposure in cats in different provinces could be related to differences in ecological and geographical factors such as temperature, rainfall, or landscape differences. The methods used to determine T. gondii prevalence were also considered as a sophisticated factor to cause the differences.

Among the 44 B1 gene positive DNA samples, 13 of them gave complete genotyping results, three were genotyped at the 10 loci. Due to low DNA concentration, 28 of the 44 positive samples could not be genotyped and was therefore not used. Genetic characterization of the 16 samples revealed five genotypes, 11 of 16 samples were identified as ToxoDB\#9, two of 16 samples may belong to genotype \#225, one was Type II, one was ToxoDB\#3, and one was ToxoDB\#20. The results of genotyping of these strains and 9 references were summarized in Table 3. ToxoDB\#9 was identified from 4 different cities of Yunnan province (Table 3), which suggests that this type is prevalent in this region. This same genotype was previously identified in cats in Beijing Municipality, Guangdong, Anhui, Guizhou, Shandong, and Hubei province $[7-9,11,19]$, and it was also found in pigs in Guangdong, Henan, Yunnan and Anhui province [10,20-22]. Therefore, ToxoDB\#9 is a predominant lineage prevalent in Mainland China. Many studies indicated that ToxoDB\#9 has been isolated in North and South America [5,23-25], as well as other Asian countries, such as Sri Lanka, Vietnam $[26,27]$, indicating that it has a worldwide distribution.

In this study, ToxoDB\#3 (the type II variant) was identified for the first time in cats in China. This type had been founded from sheep in Qinghai province [10], from birds in Xinjiang Uygur Autonomous Region [28], from sparrows in Lanzhou, Gansu province [29], and from pigs in Zhongshan, Guangdong province [30]. ToxoDB\#1 (the type II) was reported in humans [19], but this is the first report of this genotype in cats. We also founded ToxoDB\#20 from one cat in Jinping, which is the first time that this has been reported in China too. Genotype \#20 has been reported in dogs from Sri Lanka [27], feral cats in Egypt [31], stray dogs in Egypt [32], feral cats in Ethiopia [33], and sand cats in Qatar [34], indicating its wide spread from Africa to Asia. In this study we also identified a genotype most likely to be the \#225, which has been reported from chickens in China [8]. Unfortunately, the number of cat samples is small in this study, especially in Kunming, where only 4 cats were collected, due to difficulties in collection of stray cats. To obtain more accurate information about the genetic diversity of $T$. gondii in cats in this unique province, more samples from more regions in Yunnan province should be used in further studies including the serology and bioassays. The conventional multilocus PCR-RFLP method relies on single-copy polymorphic DNA sequences, and usually a relatively higher amount of starting templates from the parasite is required. Due to the low DNA concentration of some samples, some $T$. gondii positive samples could not be completely genotyped.

Based on these results, the genetic diversity of $T$. gondii is quite high in cats in Yunnan province. Yunnan has a generally mild climate with pleasant and fair weather because of the province's location on south-facing mountain slopes, receiving the influence of both the Pacific and Indian Oceans, it is China's most diverse province, biologically as well as culturally. The province contains snow-capped mountains and true tropical environments, thus supporting an unusually full spectrum of species and vegetation types. This diversity could be related to the diverse climate and biology.

\section{Conclusion}

In conclusion, the results of the present study revealed a wide distribution of $T$. gondii infection in cats in Yunnan province, which may pose significant public health concerns. To our knowledge, this is the first report of $T$. gondii prevalence and genotypes in cats in southwestern China, and the first report of Type II $T$. gondii from cats in China.

\section{Competing interests}

The authors declare that they have no competing interests.

\section{Authors' contributions}

FCZ and XQZ conceived and designed the study, and critically revised the manuscript. YMT, SYH, QM and HHJ performed the experiments, analyzed the data and drafted the manuscript. JFY and CS helped in study design, study implementation and manuscript revision. All authors read and approved the final manuscript.

\section{Acknowledgements}

Project support was provided, in part, by the Yunnan Provincial Program for Introducing High-level Scientists (Grant No. 2009CI125), National Natural Science Foundation of China (Grant No. 31228022), and China Postdoctoral Science Foundation project (2012 M511951). 


\section{Author details}

${ }^{1}$ College of Animal Science and Technology, Yunnan Agricultural University, 650201 Kunming, Yunnan Province, PR China. ${ }^{2}$ State Key Laboratory of Veterinary Etiological Biology, Key Laboratory of Veterinary Parasitology of Gansu Province, Lanzhou Veterinary Research Institute, Chinese Academy of Agricultural Sciences, 730046 Lanzhou, Gansu Province, PR China. ${ }^{3}$ Department of Microbiology, The University of Tennessee, 37996 Knoxville, TN, USA. ${ }^{4}$ School of Life Sciences, Yunnan University, 650091 Kunming, Yunnan Province, PR China.

Received: 26 February 2014 Accepted: 9 April 2014

Published: 11 April 2014

\section{References}

1. Dubey JP: Toxoplasmosis of Animals and Humans, vol. 313. Boca Raton: CRC Press; 2010.

2. Jones JL, Lopez A, Wilson M, Schulkin J, Gibbs R: Congenital toxoplasmosis: a review. Obstet \& Gynecol Survey 2001, 56:296-305.

3. Khan A, Dubey JP, Su C, Ajioka JW, Rosenthal BM, Sibley LD: Genetic analyses of atypical Toxoplasma gondii strains reveal a fourth clonal lineage in North America. Int J Parasitol 2011, 41:645-655.

4. Dubey JP, Graham DH, Blackston CR, Lehmann T, Gennari SM, Ragozo AM, Nishi SM, Shen SK, Kwok OC, Hill DE, Thulliez P: Biological and genetic characterisation of Toxoplasma gondii isolates from chickens (Gallus domesticus) from Sao Paulo, Brazil: unexpected findings. Int J Parasitol 2002, 32:99-105.

5. Dubey JP, Sundar N, Hill D, Velmurugan GV, Bandini LA, Kwok OC, Majumdar D, Su C: High prevalence and abundant atypical genotypes of Toxoplasma gondii isolated from lambs destined for human consumption in the USA. Int J Parasito/ 2008, 38:999-1006.

6. Lehmann T, Marcet PL, Graham DH, Dahl ER, Dubey JP: Globalization and the population structure of Toxoplasma gondii. Proc Natl Acad Sci U S A 2006, 103:11423-11428.

7. Chen ZW, Gao JM, Huo XX, Wang L, Yu L, Halm-Lai F, Xu YH, Song WJ, Hide G, Shen JL, Lun ZR: Genotyping of Toxoplasma gondii isolates from cats in different geographic regions of China. Vet Parasitol 2011, 183:166-170

8. Wang L, Cheng HW, Huang KQ, Xu YH, Li YN, Du J, Yu L, Luo QL, Wei W, Jiang L, Shen JL: Toxoplasma gondii prevalence in food animals and rodents in different regions of China: isolation, genotyping and mouse pathogenicity. Parasit Vectors 2013, 6:273.

9. Qian W, Wang H, Su C, Shan D, Cui X, Yang N, Lv C, Liu Q: Isolation and characterization of Toxoplasma gondii strains from stray cats revealed a single genotype in Beijing, China. Vet Parasitol 2012, 187:408-413.

10. Zhou P, Zhang H, Lin RQ, Zhang DL, Song HQ, Su C, Zhu XQ: Genetic characterization of Toxoplasma gondii isolates from China. Parasitol Int 2009, 58:193-195.

11. Dubey JP, Zhu XQ, Sundar N, Zhang H, Kwok OC, Su C: Genetic and biologic characterization of Toxoplasma gondii isolates of cats from China. Vet Parasitol 2007, 145:352-356.

12. Duan G, Tian YM, Li BF, Yang JF, Liu ZL, Yuan FZ, Zhu XQ, Zou FC: Seroprevalence of Toxoplasma gondii infection in pet dogs in Kunming, Southwest China. Parasit Vectors 2012, 5:118.

13. Zou FC, Sun XT, Xie YJ, Li B, Zhao GH, Duan G, Zhu XQ: Seroprevalence of Toxoplasma gondii in pigs in southwestern China. Parasitol Int 2009, 58:306-307.

14. You YX, Li W, Shen LJ, Nie DP: Serological investigation of Toxoplasma gondii infection in HIV positive cases in Dali and Dehong of Yunnan. Chin J Parasitol Parasit Dis 2012, 30:418-419.

15. Tian YM, Dai FY, Huang SY, Deng ZH, Duan G, Zhou DH, Yang JF, Weng YB, Zhu XQ, Zou FC: First report of Toxoplasma gondii seroprevalence in peafowls in Yunnan Province, Southwestern China. Parasit Vectors 2012, 5:205.

16. Hill DE, Chirukandoth S, Dubey JP, Lunney JK, Gamble HR: Comparison of detection methods for Toxoplasma gondii in naturally and experimentally infected swine. Vet Parasito/ 2006, 141:9-17.

17. Su C, Shwab EK, Zhou P, Zhu XQ, Dubey JP: Moving towards an integrated approach to molecular detection and identification of Toxoplasma gondii. Parasitology 2010, 137:1-11.

18. Wu SM, Zhu XQ, Zhou DH, Fu BQ, Chen J, Yang JF, Song HQ, Weng YB, Ye DH: Seroprevalence of Toxoplasma gondii infection in household and stray cats in Lanzhou, Northwest China. Parasit Vectors 2011, 4:214.
19. Wang L, Chen H, Liu D, Huo X, Gao J, Song X, Xu X, Huang K, Liu W, Wang Y, Lu F, Lun ZR, Luo Q, Wang X, Shen J: Genotypes and mouse virulence of Toxoplasma gondii isolates from animals and humans in China. PLOS One 2013, 8:e53483.

20. Zhou P, Nie H, Zhang LX, Wang HY, Yin CC, Su C, Zhu XQ, Zhao JL: Genetic characterization of Toxoplasma gondii isolates from pigs in China. J Parasitol 2010, 96:1027-1029.

21. Zhou P, Sun XT, Yin CC, Yang JF, Yuan ZG, Yan HK, Zhu XQ, Zou FC: Genetic characterization of Toxoplasma gondii isolates from pigs in Southwestern China. J Parasitol 2011, 97:1193-1195.

22. Wang H, Wang T, Luo Q, Huo X, Wang L, Liu T, Xu X, Wang Y, Lu F, Lun Z, $Y u L$, Shen J: Prevalence and genotypes of Toxoplasma gondii in pork from retail meat stores in Eastern China. Int J Food Microbiol 2012, 157:393-397.

23. Dubey JP, Velmurugan GV, Alvarado-Esquivel C, Alvarado-Esquivel D, Rodriguez-Pena S, Martinez-Garcia S, Gonzalez-Herrera A, Ferreira LR, Kwok OC, Su C: Isolation of Toxoplasma gondii from animals in Durango, Mexico. J Parasitol 2009, 95:319-322

24. Dubey JP, Cortes-Vecino JA, Vargas-Duarte JJ, Sundar N, Velmurugan GV, Bandini LM, Polo L, Zambrano L, Mora LE, Kwok OC, Smith T, Su C: Prevalence of Toxoplasma gondii in dogs from Colombia, South America and genetic characterization of T. gondii isolates. Vet Parasitol 2007, 145:45-50.

25. Dubey JP, Sundar N, Gennari SM, Minervino AH, Farias NA, Ruas JL, dos Santos TR, Cavalcante GT, Kwok OC, Su C: Biologic and genetic comparison of Toxoplasma gondii isolates in free-range chickens from the northern Para state and the southern state Rio Grande do Sul, Brazil revealed highly diverse and distinct parasite populations. Vet Parasitol 2007, 143:182-188.

26. Dubey JP, Huong LT, Sundar N, Su C: Genetic characterization of Toxoplasma gondii isolates in dogs from Vietnam suggests their South American origin. Vet Parasitol 2007, 146:347-351.

27. Dubey JP, Rajapakse RP, Wijesundera RR, Sundar N, Velmurugan GV, Kwok OC, Su C: Prevalence of Toxoplasma gondii in dogs from Sri Lanka and genetic characterization of the parasite isolates. Vet Parasitol 2007, 146:341-346.

28. Huang SY, Cong W, Zhou P, Zhou DH, Wu SM, Xu MJ, Zou FC, Song HQ, Zhu XQ: First report of genotyping of Toxoplasma gondii isolates from wild birds in China. J Parasitol 2012, 98:681-682

29. Cong W, Huang SY, Zhou DH, Zhang XX, Zhang NZ, Zhao Q, Zhu XQ: Prevalence and Genetic Characterization of Toxoplasma gondii in House Sparrows (Passer domesticus) in Lanzhou, China. Korean J Parasitol 2013, 51:363-367.

30. Jiang HH, Huang SY, Zhou DH, Zhang XX, Su C, Deng SZ, Zhu XQ: Genetic characterization of Toxoplasma gondii from pigs from different localities in China by PCR-RFLP. Parasit Vectors 2013, 6:227.

31. Al-Kappany YM, Rajendran C, Abu-Elwafa SA, Hilali M, Su C, Dubey JP: Genetic diversity of Toxoplasma gondii isolates in Egyptian feral cats reveals new genotypes. J Parasitol 2010, 96:1112-1114.

32. El Behairy AM, Choudhary S, Ferreira LR, Kwok OC, Hilali M, Su C, Dubey JP: Genetic characterization of viable Toxoplasma gondii isolates from stray dogs from Giza, Egypt. Vet Parasitol 2013, 193:25-29.

33. Dubey JP, Choudhary S, Tilahun G, Tiao N, Gebreyes WA, Zou X, Su C: Genetic diversity of Toxoplasma gondii isolates from Ethiopian feral cats. Vet Parasitol 2013, 196:206-208.

34. Dubey JP, Pas A, Rajendran C, Kwok OC, Ferreira LR, Martins J, Hebel C, Hammer S, Su C: Toxoplasmosis in sand cats (Felis margarita) and other animals in the Breeding Centre for Endangered Arabian Wildlife in the United Arab Emirates and AI Wabra Wildlife Preservation, the State of Qatar. Vet Parasitol 2010, 172:195-203

doi:10.1186/1756-3305-7-178

Cite this article as: Tian et al:: Genetic characterization of Toxoplasma gondii from cats in Yunnan Province, Southwestern China. Parasites \& Vectors 2014 7:178 